A PAISAGEM E A DESCOBERTA DO MUNDO EM "CAMPO GERAL", DE GUIMARÃES ROSA

\author{
THE LANDSCAPE AND THE DISCOVERY OF THE WORLD IN \\ "CAMPO GERAL", OF GUIMARÃES ROSA
}

\author{
Juliana Estanislau Mantovani ${ }^{l}$ \\ Sidney Barbosa ${ }^{2}$
}

RESUMO: Se a representação artística é concebida não puramente como reprodução pictórica ou literal das imagens apropriadas pelo indivíduo, mas como um processo de (re)elaboração das formas, a paisagem, na literatura, pode ser compreendida, então, como um reflexo de quem olha. No entanto, para tal compreensão, se faz necessário entender uma natureza que represente além de um cenário ou plano de fundo das ações dos personagens. É importante refletir acerca de uma representação literária que conceda à natureza o papel de elemento constitutivo da obra, ou seja, como elemento narrativo capaz de transmitir e incorporar significados relevantes ao conteúdo das obras. Assim, o vínculo da representação da natureza aos demais elementos constitutivos da obra é necessário para reconhecer em algumas obras a presença da natureza como atuante e imprescindível no transcurso da narrativa. Nesse aspecto, o artigo propõe um breve estudo da representação literária da natureza para servir como auxílio para as análises da obra "Campo Geral", de Guimarães Rosa, no que tange à representação da natureza nessa obra, porquanto, em "Campo Geral", a paisagem é erigida ao patamar de representação das descobertas do personagem Miguilim.

PALAVRAS-CHAVE: Literatura. Paisagem. Descoberta. "Campo Geral".

ABSTRACT: If the artistic representation is conceived not as purely pictorial or literal reproduction of images appropriate for the individual, but as a process of development of forms, the landscape in the literature can be understood, then, as a reflection of the beholder. However, for such an understanding, it is necessary to understand a nature that represents plus a setting or background of the actions of the characters. It is important to reflect on a literary representation to grant the nature the role of constitutive element of the work, that is, as a narrative element capable of transmitting and incorporate relevant meanings to

\footnotetext{
${ }^{1}$ Universidade de Brasília.

${ }^{2}$ Universidade de Brasília.
} 
the content of the works. Thus, the bond of representation of nature to the other constituent elements of the work is necessary to recognize in some works the presence of nature as active and essential in the course of the narrative. In this respect, the article proposes a brief study of the literary representation of nature to serve as an aid to the analysis of the work "Campo Geral", of Guimarães Rosa, regarding the representation of nature in this work, because, in "Campo Geral", the landscape is erected to the level of representation of Miguilim character's findings. KEYWORDS: Literature. Landscape. Discovery. "Campo Geral". 


\section{A PAISAGEM E A DESCOBERTA DO MUNDO EM "CAMPO GERAL", DE GUIMARÃES ROSA}

A palavra paisagem, cheia de conceitos e significações diversas, requer uma delimitação para seu uso e uma explanação acerca das implicações ideológicas embutidas em torno de sua limitação. Para os estudos da geografia, é a paisagem um conceito-chave; dessa forma, trata-se de um conceito que fornece e estabelece a unidade e a identidade para a própria geografia. Em um breve percurso pelo conceito e pela discussão sobre a paisagem nos caminhos da geografia, é possível se aprofundar acerca da temática, bem como desenvolver esclarecimentos para a conceituação literária e a sua forma de representar a paisagem.

É relevante notar que, para os geógrafos franceses Chantal Blanc-Pamard e JeanPierre Raison, essa palavra de uso cotidiano, a paisagem, é usada por cada pessoa ao seu modo e foi se tornando um vocabulário de senso comum. Ainda para os autores,

\footnotetext{
Paisagem, uma destas noções utilizadas por um número sempre crescente de disciplinas, que muitas vezes ainda se ignoram. Paisagem, enfim, um dos temas clássicos da investigação geográfica. Conforme o interesse do que é objeto ou uma maneira como se encara a própria noção de paisagem difere. Se um geógrafo, um historiador, um arquiteto se debruçarem sobre a mesma paisagem, o resultado de seus trabalhos e a maneira de conduzi-los serão diferentes, segundo o ângulo de visão de cada um dos que a examinam. (CHANTAL e RAISON, 1986, p.138, grifos nossos)
}

Tal discussão é fecunda no que tange aos usos da palavra paisagem na representação literária, uma vez que a paisagem será encarada, de modo geral, como um enquadramento visual, uma escolha parcial da natureza pelos olhos admirados de um espectador. E é importante salientar que é através da paisagem, dentre as diferentes formas de contato do homem com a natureza, que fica evidente uma forma de projeção dos indivíduos sobre os objetos e os elementos a respeito dos quais desejam refletir. A paisagem, assim, pode ser considerada como uma projeção do homem, a partir de seus olhos e suas escolhas, sobre a natureza.

Nesses termos, pode-se, então, pensar em uma paisagem subjetiva, visto que não é possível se definir a paisagem desvinculada de um espaço - que é cultural e social -, de um contexto, de uma cultura, de uma sociedade e de um indivíduo. Dessa forma, é relevante 
resgatar a noção de paisagem como a forma de conexão - ou projeção - dos seres humanos com a natureza, ou ainda de uma delimitação escolhida e limitada da natureza pelo enquadramento e pelo olhar humano.

Produtivo é também observar que o dicionário traz por definição de paisagem justamente "uma extensão de território que se abrange com um lance de vista, panorama, vista" ou ainda como uma "pintura, gravura ou desenho que representa ou em que se descreve um sítio, natural, rural ou urbano". Essas definições levam a compreender que a paisagem abrange um aspecto visual e seletivo do indivíduo que se relaciona com a natureza, que a observa. No contato do homem com a paisagem,

\begin{abstract}
Ocorre como se sujeito e objeto estético estivessem envolvidos intrinsecamente de tal modo que o segundo dependesse tanto do primeiro que este determinasse até mesmo a sua própria existência, e, muito mais seus atributos. Essa existência depende, quase que inteiramente, do sujeito que olha. (BARBOSA, 2005, p.78, grifo nosso)
\end{abstract}

A paisagem, compreendida como um atributo criado e mantido a partir de um sujeito e de uma cultura e uma sociedade, é caracterizada como um quadro visual escolhido através de uma harmonia subjetiva, uma percepção individual, uma visão particular e cuja existência estará atrelada ao modo como o sujeito a olha, a percebe, a sente.

Dessa maneira, falar em paisagem é falar em um ponto de vista - subjetivo e único, ao mesmo tempo, emotivo e intelectual. Portanto, conceituar a paisagem é aproximá-la das noções de criação, invenção e imaginação, já que para se produzir uma paisagem, ou percebêla, é necessário fixar o olhar, escolher, enquadrar uma parte da natureza, e é esse ponto de vista que poderá ser captado e representado artisticamente.

Essa valorização do sujeito que realiza a ação de observar já estava presente na Antiguidade Clássica. René Martin fala em uma "école du regard" (Martin apud Barbosa, 2005, p.78), destacando o valor dado pela Antiguidade Clássica para a apreensão do universo, através de um aprendizado de contemplação, de um gesto libertador e fundador de levar os olhos, olhar para o alto e explorar o universo infinito. Essa contemplação, esse olhar para cima está presente na prática de observação da natureza, com a finalidade de vislumbrar o universo.

Assim, é importante notar que o tema da paisagem está intrinsecamente ligado ao modo de olhar do sujeito que explora, observa, admira, contempla... É pela escolha visual que a paisagem subjetiva de cada indivíduo é percebida, e a mudança do modo de relacionar-se com a natureza gera uma consequente alteração da paisagem percebida a partir desse novo olhar.

Em outras palavras, equivale dizer que o homem relacionado com a natureza a partir do prisma da dominação será capaz de enquadrá-la em seu campo visual de um modo totalmente diferente daquele que se consorcia e se religa com a natureza, estabelecendo com ela uma relação de pertencimento e de complementariedade. A paisagem para o homem dominador que oprime e explora a natureza será uma... A paisagem para o homem que se deleita será outra...

E é interessante compreender, portanto, que a paisagem do homem que convive, se religa e contempla a natureza será, em sua essência, a sua própria imagem refletida. $\mathrm{O}$ encontro com a natureza manifesta uma autorreflexão libertadora, e a paisagem é o espelho pelo qual é refletida a imagem daquele ser e da relação que ele cria e mantém com a natureza, trata-se, portanto, "de um ponto de vista imaginário que coloca o sujeito que olha, no momento de visualização da paisagem, como sendo, momentaneamente, o centro do mundo." (BARBOSA, 2005, p.81, grifos nossos). 
Dessa forma, é pertinente complementar que esse objeto de eleição e valoração de certos conjuntos de elementos da natureza (a paisagem) deve estar forçosamente carregado de sentimento, de afeto. A paisagem, como uma escolha individual capaz de refletir a própria relação que o sujeito estabelece com a natureza, é um forte elemento que modifica os estados da alma do ser humano e, conforme o crítico literário Raul Castagnino, "A paisagem oferece a óptica e as tonalidades do estado de ânimo" (Castagnino apud Barbosa, 2005, p.80).

Essa religação do homem com a natureza, traço imprescindível para a concepção rosiana, engloba essa mudança de posicionamento diante do mundo e a alteração da maneira como o sujeito olha e vê os elementos ao seu redor. A paisagem captada por um olhar infantil, genuíno e ingênuo traz uma força reveladora e uma representação simbólica desse contato nupcial e complementar com a natureza.

O homem renovado - ou a criança - é capaz de redirecionar os seus olhos para a natureza, e a paisagem (ou seja, o quadro vislumbrado) que pode ser captada por esse olhar revela que contato íntimo esse ser estabelece com a natureza. Pode-se dizer, assim, que a paisagem apreendida pelo indivíduo revela que relação ele estabelece diante daquela imensa natureza, do mundo infinito.

Em "Campo Geral", é um olhar assustado e ingênuo, admirado e espantado, que observa as paisagens do sertão. Se Miguilim vincula-se à natureza intimamente, busca, então, captar com seus "pequenos" olhos a sua imagem e a imagem do mundo refletida nas páginas daquela paisagem que ele curiosamente espia, olha, revisa, observa, contempla e admira... Os olhos de Miguilim, em busca de enxergar a paisagem, refletem a sua religação com o mundo e, por isso, a sua travessia surgirá pelos contatos com a paisagem percebida e vivida por ele.

A obra "Campo Geral" possui uma grande força simbólica especialmente no que diz respeito ao processo de aprendizagem da criança e de sua perspectiva de visão infantil. Assim como explorado em outras obras, como em "As margens da alegria" e em "Os cimos", a construção narrativa rosiana engendra a perspectiva visual infantil como princípio norteador e guia dos novos caminhos pelas paisagens do sertão. A narrativa de viagem nessas obras toma proporções únicas, tendo em vista o contato virgem e iniciatório dos meninos com o mundo e as paisagens do sertão.

A percepção do inédito, inesperado e genuíno explode das páginas de "Campo Geral" ditando os percursos a serem seguidos pelos olhos igualmente virgens de seu leitorviajante. É a perspectiva visual infantil que emerge e pulsa nessa narrativa de descobertas e revelações, e o modo de construção arquitetônica de Guimarães Rosa é investido a fim de perpetuar um perspectivismo narrativo híbrido e cativante, já que em "Campo Geral" o narrador veste máscaras servindo como um mediador de seus personagens.

Tal narrador é compreendido por Ronaldes de Melo e Souza como um "narrador epilírico" (SOUZA, 2008), que em $3^{\mathrm{a}}$ pessoa limita sua visão e torna transparente o ponto de vista, ou seja, revela a percepção visual através da experiência da criança narrada, e assim incorpora a máscara de outrem e dramatiza a realidade narrada através da dupla mediação. Dessa forma, junta-se ao gesto impessoal de limitação de ponto de vista de um narrador épico o transbordamento do tom lírico entusiasmado do menino - cujo fascínio mistura-se ao deslumbramento do próprio narrador.

A importância da travessia, do aprendizado, ou da experiência do jogo simbólico das interações com a natureza e com vida, pode ainda ser analisada como mote central em "Campo Geral", e nessa narrativa a valoração da experiência se constrói através da mundividência ou visão criadora e poética dos meninos contadores de estórias.

Essa narrativa comandada pelo narrador epilírico abre margem à visão poética da imaginação criadora infantil, que não aceita (ou, ao menos, reivindica uma nova visão para) a lógica das pessoas grandes, porquanto o menino Miguilim é um grande experienciador da vida, um contemplador maravilhado pela (i)lógica poética do sertão e das palavras... 
E, por isso, conforme esclarecido pelo autor em conversa com seu tradutor italiano Edoardo Bizzarri (ROSA, 2003), "Campo Geral" contém todos os germes, os motivos, os temas das demais estórias de Corpo de Baile: a iniciação na arte de contar estórias (e reinventar poeticamente a existência) e a visão do cosmos sertanejo como a marca simbólica da fusão, do vínculo nupcial entre o homem e o mundo.

A novela "Cara-de-bronze" e sua interpretação igualmente fortalecem a intenção em vincular o mote de "Campo Geral", germe central do livro, no caso a (re)invenção da existência, à percepção visual renovada. Em "Cara-de-bronze" tem-se a busca do fazendeiro poderoso e rico, mas triste e exilado, imobilizado pela paralisia "(que é a exteriorização de uma como que "paralisia da alma')" (ROSA, 2003, p.94) de encontrar a poesia e, para isso, pede ao jovem Grivo que saia para ver as coisas e, tomando seus olhos de empréstimo, possa trazer para si a beleza daquilo que ele já não podia.

O Cara-de-Bronze, velho misterioso, examina seus vaqueiros a fim de escolher aquele que teria a mais viva e apreensora sensibilidade de captar a poesia das paisagens e dos lugares de sua terra para levar a beleza até ele. Interessante é notar que o fazendeiro solicita aquele que estaria apto a captar a poesia das paisagens e dos lugares, isso é, captar a poesia visual! Tem-se aqui, portanto, a busca da poesia pela imagem, pelo sentido da visão! O belo perseguido é a visão nítida e plena das paisagens do sertão, e é somente esse contato genuíno e primordial do homem com o mundo pela sua percepção visual que o faz encontrar-se com a beleza e consigo.

O que o vaqueiro Grivo vai buscar, a sua demanda é, enfim, a própria poesia, personificada nas belezas do sertão, como podem ser notado nas notas de rodapé da novela os nomes das árvores vistas durante a viagem, e as árvores citadas, conforme Rosa, são as que "contém poesia" em seu nome.

É relevante lembrar também que "há um oculto desabafo lúdico, pessoal e particular brincadeira do autor, só mesmo para seu uso, mas que mostra a Você, não resisto: 'Aí, Zé, ôpa!', intraduzível evidentemente: lido de trás para diante = apô Éz ía, : a Poesia" (ROSA, 2003, p.93). E tudo o que Grivo trazia - a sua demanda poética - era só o que viu, o que observou: "Em lugares, muito vi os buritis morrendo: briga da caatinga com o Gerais... Buriti-bravo: é espinhoso... As aves: - Garças são as mais que são as mesmas: garça quara madapolão... Viu o gado folheiro, comendo árvores dos matos" (ROSA, 2006, p.618)

A ingenuidade infantil, metáfora sublime do renascimento da percepção dos homens, é a potência aclamada por um narrador entusiasmado com as novas descobertas das viagens e travessias de Miguilim. A visão dos adultos encontra-se encarcerada pela lógica de ordenação das causas do mundo e pela lógica de dominar ou ser dominado - o que, portanto, impossibilita o homem grande (e não renovado, não renascido) de enxergar a beleza da vida e dos campos gerais (e mesmo do Mutúm!).

É nítida, aliás, a análise de Miguilim sobre os adultos, como seu Pai Bernardo e sua Mãe Nhanina: aquele violento, autoritário e suicida, e essa triste e pessimista com relação à vida. Para Miguilim, as conversas adultas eram sempre sobre coisas secas com necessidades de serem brutas. Tal opinião faz, inclusive, com que o protagonista não deseje crescer, é melhor inventar estórias, para poder experimentar outras vidas, outras experiências.

Se para Manuel Bandeira reivindica-se a poética pelo "lirismo dos loucos/ o lirismo dos bêbados", em "Campo Geral" a poética da visão criadora infantil é erigida ao patamar da fonte perene da poesia; essa renovada visão poética transcende a inércia do espírito subjugado pelos fatos e assume o infinito poder do encantamento. O lúdico da experiência infantil transforma o real em matéria dinâmica, metamórfica, em que a vida não se resume ao domínio e à manipulação, não se resume à subsistência, mas antes experimenta a si mesma como um ato contemplativo da autocriação. Nessa perspectiva, a força modificadora do homem reside em seu poder criativo e inventivo, e tal força Miguilim encontra nos contadores 
e (en)cantadores das palavras, Dito, Grivo e Seo Aristeu. Assim, a aventura de Miguilim na vida revela o encoberto, o inexplorado e, portanto, carrega a força da conotação de saga, como sagen, do canto ou estória inaudita, inédita - e, porque não inventada?

O pensamento infantil descontrói a lógica e seus mecanismos dominantes, não obedece a ela e, para isso, cria novas possibilidades, cria estórias inventadas; o infante possui a função mitopoética de contador de estórias novas, "inventadas de juízo". Isso porque jamais a natureza, o homem e - também - a linguagem se conformam com o externo apresentado estático e acabado, e a voz infantil inaugura um dinamismo que anseia pela metamorfose, uma dinâmica da vida livre dos liames deterministas do logicismo casual. A criança de Rosa interpreta o papel do homem novo, renovado - porta-voz do projeto de novos paradigmas da compreensão humana, que pretende renovar a si mesmo e ao mundo.

Dito, um infante (que não fala logicamente, mas poeticamente), com o poder criativo da palavra poética ensina Miguilim a deixar a tristeza de lado e a compreender a não se abater com a mãe, mas aprender o que, de modo epifânico, Dito aprendeu: "é que a gente pode ficar sempre alegre, alegre, mesmo com toda coisa ruim que acontece acontecendo. A gente deve de poder ficar então mais alegre, mais alegre, por dentro !..."(ROSA, 2006, p.100)

Seu Aristeu é um músico tocador de viola e (en)cantador de palavras poéticas e que, nas "Geórgias", de Vírgilio, remete a figura do pastor e músico detentor do conhecimento da indestrutibilidade da vida em si mesma; em "Campo Geral" mostra-se para Miguilim como capaz de espantar a tristeza pela palavra cantada e inventada e, trazendo a alegria de ouvir estórias e poder encarnar vários papéis, de curá-lo de sua enfermidade.

A transcendência da lógica é transfigurada por Rosa para a visão mitopoética do sertão, do homem, do mundo e, nessa narrativa, o regente é o pensamento infantil, já que a imaginação dos meninos suplanta, ultrapassa a lógica adulta. E a nova visão apreendida por Miguilim ao longo de sua travessia o fará perceber a beleza nas paisagens, em que ninguém parecia notá-la. A poesia encarna a nova forma de ver o mundo, deixando a paisagem revelar o encoberto, o escondido, pela experiência inédita da contemplação do menino.

Essa saga do Menino Miguilim é iniciada pela experiência genuína da viagem, uma viagem com seu Tio Terez para sua crisma. Nessa viagem, os olhos de Miguilim, virgens, puros, ingênuos, sofrem um deslocamento pela aturdida lembrança da resposta obtida de alguém sobre o Mutúm: "É um lugar bonito, entre morro e morro, com muita pedreira e muito mato, distante de qualquer parte; o lá chove sempre" (ROSA, 2006, p.11).

Sua mãe, porém, se doía de tristeza de viver ali. Ao retornar de sua viagem, Miguilim está ansioso, pois seu maior pensamento era alegrar e consolar sua mãe, dando-lhe a notícia de que um o homem havia dito " - que o Mutúm era lugar bonito..." (ROSA, 2006, p.12). Miguilim tinha essa revelação como um presente, uma salvação para sua pobre mãe. Ela, ao ouvir a narrativa de seu filho, entretanto, não the deu qualquer valor e olhando, triste, apontando o morro, disse: "Estou sempre pensando que lá por detrás dele acontecem outras coisas, que o morro está tapando de mim, e que eu nunca hei de poder ver..." (ROSA, 2006, p.12, grifos nossos). E Miguilim, embora não soubesse ainda distinguir o que seria um lugar bonito ou feio, e ainda que ele mesmo não visse a beleza do Mutúm, achava que o moço tinha razão e não a mãe.

O Mutúm se apresenta ao leitor, portanto, sob a possibilidade de duas visões: a da aceitação de Miguilim sobre a beleza do Mutúm e, assim, um lugar bonito e inventado pela sua visão criadora; e a de sofrimento e tristeza, agarrada aos ditames do mundo, da mãe de Miguilim. Há um Mutúm, uma paisagem, sob a perceptiva infantil, indagadora, conquistada e simbólica de Miguilim e um Mutúm "tão sozinho, tão escuro, o ar ali era mais escuro" (ROSA, 2006, p.12), a partir da perspectiva prisioneira do olhar da mãe de Miguilim.

E a mãe estava certa: acontecem sim coisas que ela não pode ver. Mas não é o morro que as está tapando, o que a impede de percebê-las é, justamente, seu modo limitado e lógico 
de olhar para a natureza e para si mesma. A tristeza sempre presente na existência da mãe de Miguilim encerra dentro dela uma ordem limitante, impedindo-a de perceber o que está escondido por detrás dos morros... Miguilim, contudo, reivindica e encena o aprendizado de uma nova forma de olhar o mundo!

Não à toa terá dito e ensinado o papagaio Papaco-o-Paco "Olerê lerê lerá, morena dos olhos tristes, muda esse modo de olhar..." (ROSA, 2006, p.84), pois somente mudando o modo de ver as coisas, abrindo a contemplação da natureza e suas belezas, o homem estará apto a desprender-se de sua escravidão racional e pronto para renovar-se, morrendo e renascendo para a alegria! A tristeza persiste, enquanto os olhos cansados, lógicos, físicos, presos à aparência, não conseguir senão enxergar a tristeza, enquanto seus novos olhos poderão capacitá-lo a ver a alegria, mesmo em meio a tantas tristezas...

A travessia de Miguilim é permeada pelas suas descobertas ingênuas e desapercebidas pela trivialidade adulta, que metaforicamente se apresentam pelo vislumbre das paisagens que ele é capaz de ter... A descoberta do mundo e de suas tormentas e dores, a revelação entusiasmada de suas alegrias e belezas fazem de Miguilim o verdadeiro representante do homem renascido, guiado pelo sentido da visão, perfazendo seus esclarecimentos no encontro com as paisagens: os bois e os matos do sertão dos gerais!

E a reivindicação da nova perspectiva visual justifica a escolha do autor pelo uso de uma narração em $3^{a}$ pessoa, porém mediadora da própria experiência inesperada e encantada do pequeno menino. O narrador, em seu distanciamento objetivo, mostra-se como um cúmplice do protagonista e deixa, em verdade, transparecer e transbordar nas páginas de sua narração a voz ingênua de um porta-voz das maravilhas do sertão!

Ao final da novela, sua epifania e esclarecimento, sua revelação e descoberta dos sentidos do mundo, virá! A sua escondida miopia será apresentada e contornada, pondo Miguilim diante de tudo o que antes não vira e agora pode, de modo simbólico e epifânico, ver!

A representação poética do aprendizado da nova visão infantil, pura, renovada, genuína dispõe-se nas páginas de "Campo Geral" em forma da mais bela metáfora de pôr os óculos... E sua revelação final, de uma vista renovada, de um modo novo, único, primeiro e claro, clarinho de ver o mundo faz o leitor se encantar e querer também aprender com Miguilim a ver claramente e a estar sempre alegre!

Dolorosa como sempre, a metáfora aguda do esclarecimento visual faz Miguilim chorar, faz suas lembranças ressurgirem, e traz seu confronto pessoal consigo e com a sua forma de existência, sua casa, sua família. O encontro com o doutor e, consequentemente, com seus óculos, põe Miguilim em um pacto pleno de aprendizagem sobre um mundo enorme, grandioso, e muito maior do que seu meio de caminho, Mutúm.

A sua epifania se transforma no pacto consigo mesmo de enxergar novamente o mundo e todos que ele já vira, fazendo-o confrontar-se com seus sonhos e desejos, com suas angústias e medos, com sua realidade; Miguilim transpõe a lógica da ordem racional de olhar e só ver o que é físico, vestindo em si um novo olhar, um olhar potencialmente concebido em suas travessias infantis e em seus contatos com a natureza.

A miopia concentra a força metafórica do aprendizado da nova visão, com cuja renovação capacita Miguilim a ver o mundo, as paisagens, sua mãe, o doutor, seus irmãos e o Mutúm. Capacita-o, enfim, a ver pela primeira vez o que o morro escondia e ele tanto aspirava a ver... E, pondo os óculos, se regenera, se transforma, se tornando apto a ver o inexplorado, o inédito o invisto, o invisível: que o Mutúm era bonito!

Olhava mais era para Mãe. Drelina era bonita, a China, Tomezinho. Sorriu para o Tio Terez: — "Tio Terez, o senhor parece com o Pai..." Todos choravam. O doutor limpou a goela, disse: - "Não sei, quando eu tiro esses óculos, tão fortes, até meus olhos se enchem d'água..." Miguilim entregou a ele os óculos outra vez. Um 
soluçozinho veio. Dito e a Cuca Pingo-de-ouro. E o Pai. Sempre alegre, Miguilim... Sempre alegre, Miguilim... Nem sabia o que era alegria e tristeza. Mãe o beijava. A Rosa punha-lhe doces-de-leite nas algibeiras, para a viagem. Papaco-o-Paco falava, alto, falava. (ROSA, 2006, p.133)

Se agora, antes de partir, Miguilim olha novamente para todo o Mutúm, é porque é capaz de revê-lo. Esse ato de olhar permite a ele e ao leitor passarem pelo processo de perceber visualmente a nova realidade, e isso a partir de uma nova ótica, de uma nova perspectiva. A narrativa, que fora toda mediada pelo narrador sob o movimento duplo e dinâmico da perspectiva do olhar infantil e assustado de Miguilim - sob a construção da narrativa personativa -, não perde seu tom de maravilhamento e epifania, isso é, de encontro com o mistério, com o inesperado, com a regeneração, e torna a deixar transparecer a percepção (ou nova percepção) da criança vislumbrada.

E se a miopia mostra-se como uma limitação de ordem física - o que fazia Miguilim não ver e esbarrar nas coisas e ser incapaz de realizar algumas tarefas com competência, desajeitado -, nessa estória ela representa a visão de um mundo impressionante, sob os olhos do menino míope, um mundo que, visto desse novo modo, é, então, redescoberto e revelado!

Nessa narrativa, a disjunção visual e física da visão transporta-se para o plano do simbólico, revelando-se com o princípio capaz de trazer a epifania existencial de Miguilim: "Há um modo de ver que ultrapassa as limitações da miopia, e curiosamente, talvez seja justamente a miopia o elemento de transcendência necessário para que o menino possa ver o mundo da forma como o vê." (SANTOS, 2006, p.224, grifo nosso).

E, dessa maneira, a miopia de Miguilim deve ser tida como um elemento alegórico, cujo valor é metafórico, funcionamento como um símbolo de uma visão especial, única, ampliada, potencializada: "Este jeito fisicamente desajeitado de ver o mundo e existencialmente profundo de questioná-lo faz-nos pensar em uma expansão do olhar." (SANTOS, 2006, p.225).

Ao fim dessa trágica estória, o leitor é convidado igualmente a fazer uma re-visão de tudo o que vira, do lugar, do espaço, das paisagens e da própria existência, pois imerso em angústias e sofrimentos, o protagonista irrompe numa epifania mágica de aprendizado, de renovação das possibilidades de existências, de compreensão da não-lógica da vida, de aceitação das metamorfoses... O leitor-viajante, que é contraposto às suas expectativas e vislumbra o ser infantil que acaba de aprender a ver de modo novo a paisagem do sertão e a ver a alegria no meio das tristezas, é conduzido, pelo pacto com seu protagonista e pela descrição visual renovada da paisagem feita por Miguilim, a rever seus conceitos, aprendendo também a perceber nas coisas simples e imperceptíveis a possibilidade de existir, a possibilidade de alegrar-se, mesmo com as coisas ruins que acontecem.

Miguilim traduz a percepção das coisas pequenas e insignificantes aos olhos lógicos e adultos: ele vê a vida e a poesia pulsante, a matéria vertente... Ele vê os cachorros, os bois, o tatu, as formigas, o rastro branco dos caramujos, a Cuca- Pingo- de- Ouro, o cachorro Gigão, o papagaio Paco-o-Paco... Ele vê, pelas pequenas paisagens que o circundam, o mundo infinito!

Miguilim representa o homem renovado porque ele olha perguntando, indagando e aprendendo. $\mathrm{O}$ homem renascido deve ser marcado pelos olhos de aprendiz! Assim, essa visão renovada do homem novo está marcada pela visão infantil e deve ser destacada pela epifania final de Miguilim que, colocando seus óculos, pode ver como o Mutúm era bonito.

Sendo Mestre não aquele que sempre ensina, "mas quem de repente aprende", é a forma de se relacionar com o mundo, pela perspectiva dos olhos virgens e aprendizes de uma criança o grande ensinamento ético e filosófico construído por Rosa para a travessia da existência dos homens. 
E, caso aprenda a enxergar com os mesmos olhos virgens e infantis, o leitor-viajante é convidado a chorar com Miguilim e a se regenerar, se modificar - abrindo sua percepção visual ao belo e à poesia escondida nas paisagens do sertão dos campos gerais!

\section{REREFÊNCIAS}

BARBOSA, Sidney. A representação da natureza no romance francês do século XIX. Tese (livre-docência). São Paulo, UNESP, Araraquara, Faculdade de Ciências e Letras, 2005.

CHANTAL, Blanc-Pamard e RAISON, Jean-Pierre. Paisagem. In: Enciclopédia Einaudi. v.8. 1986. Lisboa: Imprensa Nacional. p.138-159

ROSA, João Guimarães. Corpo de Baile. Edição comemorativa de 50 anos. Rio de Janeiro: Nova Fronteira, 2006. v.I e II.

. João Guimarães Rosa: correspondência com seu tradutor italiano Edoardo Bizzarri. Rio de Janeiro: Nova Fronteira; Belo Horizonte, MG: Ed. da UFMG, 2003.

. Primeiras Estórias. Rio de Janeiro: Nova Fronteira, 2005.

SANTOS, Iolanda Cristina dos. O aprendizado do olhar na obra de Guimarães Rosa. Tese (Doutorado em Ciência da Literatura - Poética). Rio de Janeiro: Universidade Federal do Rio de Janeiro - UFRJ, Faculdade de Letras, 2006.

SOUZA, Ronaldes de Melo. A saga rosiana do sertão. Rio de Janeiro: EdUERJ, 2008.

Recebido em: 03 de fevereiro de 2015.

Aceito em: 08 de julho de 2015. 